\title{
ESTIMATION OF BOUNDARY LAYER THICKNESS AND DRAG COEFFICIENTS IN A FLUID SYSTEM
}

\author{
Juan Carlos Beltrán-Prieto \& Karel Kolomazník
}
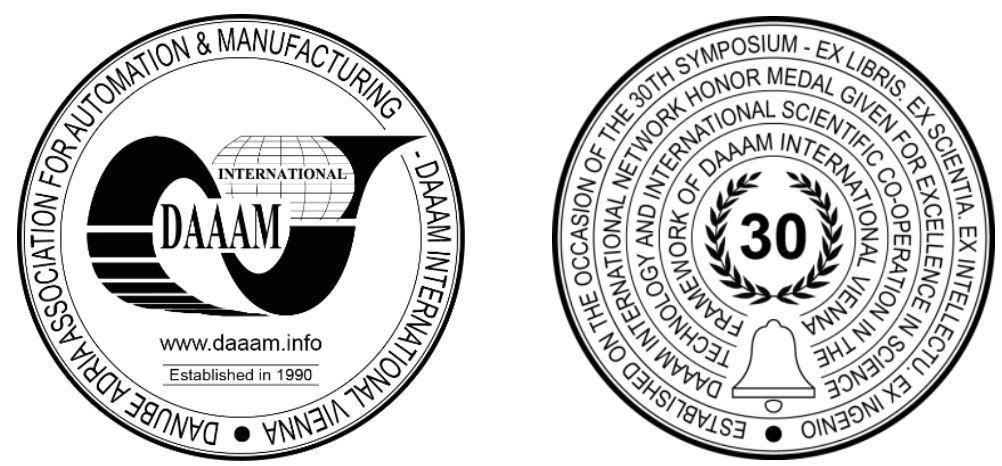

This Publication has to be referred as: Beltran-Prieto, J[uan] C[arlos] \& Kolomaznik, K[arel] (2019). Estimation of Boundary Layer Thickness and Drag Coefficients in a Fluid System, Proceedings of the 30th DAAAM International Symposium, pp.0673-0680, B. Katalinic (Ed.), Published by DAAAM International, ISBN 978-3-902734-22-8, ISSN 1726-9679, Vienna, Austria

DOI: $10.2507 / 30$ th.daaam.proceedings.092

\begin{abstract}
Over the years, many of the most demanding industries have relied on fluid flow analysis and process design to ensure proper operation and to maximize profitability and operational safety. It is well known that many of the fluids used in industrial applications behave in turbulent regime. As a result, clear and proper understanding of parameters such as transitional flow, measurement of instantaneous velocity in a fluid stream, flow behavior at lower and higher velocities inside tubes or pipes and resistance of an object in a fluid environment is important. In the present paper we study the laminar boundary layer on a flat plate and also discuss the case of turbulent flow using integral momentum balance for the boundary layer to obtain a general momentum integral relation after using an empirical or assumed velocity distribution. Furthermore, we determine the boundary layer thickness and discuss two methods to estimate drag coefficient at different distances from the leading edge. Results from the current research can be applied by the industry to model complex parameter dependencies and to estimate and simulate the presence of drag on solids with particular geometrical properties of size and shape.
\end{abstract}

Keywords: boundary layer; drag coefficient; laminar flow; leading edge; turbulent flow.

\section{Introduction}

When a viscous fluid flows in contact with a tube or pipe at a low speed, no intermingling of fluids occurs, then the fluid in contact with the tube will reduce its speed slightly in the boundary layer and heat will flow to or from the tube wall by conduction and or convection. As the velocity increases, at some point it changes into a turbulent regime. In a turbulent flow, it is assumed that vortices of different scales that interact with each other will also be present, where the boundary layer breaks and separates from the tube wall and the fluid will mix with the innermost part of it. The speed of this phenomenon will depend on several factors, such as the viscosity of the fluid, the roughness of the tube wall, the shape of the tube, its size, etc. [1] To quantify turbulence, there exist a dimensionless parameter called Reynolds number $(\mathrm{Re})$, which relates the hydraulic diameter of the tube $(\mathrm{m})$, the velocity of the fluid $\left(\mathrm{kg} / \mathrm{m}^{2} \cdot \mathrm{s}\right)$ and its viscosity $(\mathrm{kg} / \mathrm{m} \cdot \mathrm{s})$. After experimental results, it has been determined that for $\mathrm{Re}<2 \times 10^{3}$, the flow is not separated from the tube wall, and is referred to be as laminar flow. 
At the boundary layer between the solid and liquid interface corresponds a fluid velocity value of zero, additionally, the velocities close to the solid surface are small. As a result, laminar flow is present very near the surface most of the time, however, in some cases the velocity profile can be disrupted if the outer region of the boundary layer or eddies from the main portion of the flow moves closer to the wall, which can affect considerably temperature or concentration profiles during fluid mass transfer, or heat transfer to or from the wall. The flow can change into turbulent regime when the velocity of the fluid increases, particularly farther away from the surface. Thus a transition layer of intermediate character is formed between these two zones [2]. It has been suggested that a viscous sublayer, a buffer layer, and a turbulent zone are formed at the turbulent boundary layer. After experimental studies on mass transfer, it has been found that some eddies penetrate all the way through the boundary layer and reach the wall, thus the formation of a completely viscous sublayer is still under consideration. The boundary layer is thin and with features of a laminar flow near the leading edge but downstream from the leading edge, as distance increases, the boundary layer thickens, velocities arise consuming the laminar boundary layer and turbulence appears [3]. The value of thickness of the layer increases with the distance from leading edge of the plate $(\mathrm{x})$ at a value equal to $\mathrm{x}^{0.5}$ during laminar flow, then increases with $\mathrm{x}^{1.5}$ when turbulence occurs and finally with $\mathrm{x}^{0.8}$ after turbulence is fully developed.

The nature of the flow, (laminar or turbulent flow) is determined by Reynolds number, which is the number that gives the characteristics of a fluid, since it is the quotient of inertial forces and viscous forces. Reynolds number is defined by $R e=(\bar{v} \delta \rho) / \mu$, where the parameters relate to the properties of the fluid, i.e. $\bar{v}$ correspond to the flow velocity of the fluid, $\delta$ the fluid thickness, $\rho$ is the density and $\mu$ the viscosity [4]. In all flows there exists a value of this ratio for which the transition from laminar flow to turbulent flow occurs, usually referred to as the critical Reynolds number [5]. When this parameter is between $10^{5}$ and $3 \times 10^{6}$ turbulent flow starts to be present. However, in cases where there is higher turbulence and rough plate or lower turbulence and smooth plate the transition will occur at lower Reynolds numbers.

Understanding of Reynolds parameter is important for the proper understanding of fluid systems. One example is the flow of fluids through pipes or tubes. In this system, a boundary layer is formed at the entrance to the tube and as the liquid continues flowing the value of $\delta$ increases and the boundary layer is present in an increasing portion of the tube area until the boundary layer occupies the entire cross section of the stream, where the velocity distribution is constant and the flow becomes fully developed. The length required to obtain a fully developed flow is denominated as transition length $\left(x_{t}\right)$. This parameter can be evaluated after determining the diameter of the tube $(D)$ and the Reynolds number. This relationship is expressed as $x_{t}=0.05 \cdot R e \cdot D$.

Once the fluid is far from the solid surface in flow parallel with the plate, the layer and velocity gradient will remain for an amount of time until the gradients will cease to exist, the boundary layers will interlace and dissipate until the fluid reaches a uniform velocity. In case of flow perpendicular to the plate, the formation of vortices is favored with a large pressure loss in the fluid. The separation in the boundary layer occurs once a sudden variation of fluid velocity occurs and the fluid is no longer adhered to the solid surface. This leads eventually to large energy losses and as a result, it is desired to avoid boundary layer separation by removing some amount of liquid into the solid surface at the most probable separation zone or by reducing sudden changes in the surface area of the flow channel. There could be, however, cases where the separation is desired as it can be during heat transfer process or fluid mixing systems.

When the flow rate increases, small group of fluids normally denominated as eddies influence and affect the streamline as they move in several directions. The physical experimentation of transitional and turbulent flow has been carried out by different means, such as with the injection of dye, ink stream, hydrogen or small particles that participate as flow markers, into a fluid flow followed by photographic record or video which allows further observation of three dimensional motion and stereoscopic flow visualization.

Reynolds number is helpful to predict empirically the laminar-turbulent transition point. This transition stars to be present after the shear stress or shear rate at the wall in the flow increases up to a point when the laminar flow is no longer stable and the transfer of momentum is higher.

The slope of the velocity profile at the wall in laminar pipe flow is proportional to the pressure drop. The velocity profile becomes steeper after a pressure drop increment. The transition can be caused by any roughness, flow pulse or even a system vibration. The existence of the no slip at the wall boundary condition forms a boundary layer. Initially, the velocity profile approaching the leading edge of the plate is flat but as the fluid progresses along the plate, the boundary becomes thicker, causing instability to the flow and transition into a turbulent regime. It is very common that the precise transition point will vary with time over small range of distance values. Some parameters that affect the location of this point are the physical characteristics of the solid, particularly the roughness of the leading edge as well as its shape and degree of turbulence in the free stream. There exist, however instability that occurs between two fluids due to variation in fluid densities. As a result, both fluids try to reduce their combined potential energy by forcing its way up or down. When the lightest fluid is at the top of the interface it is stable, but if the heaviest fluid is at the top, then the balance of the system is unstable at interface disturbances and both fluids begin to mix. Once a small amount of heavier liquid moves down with an equal volume of lighter liquid up, the potential energy is now lower than the initial state, therefore, the disturbance will grow and lead to turbulent circulation. This phenomenon is also known as Rayleigh-Taylor instability and has a considerable effect on the climate of the Earth. This is explained by the fact that water properties near the surface of oceans are able to change leading to variations in flow of warm water that is transported from one region to another.

The nature of the fluid transition state has been deeply investigated over the past years and is still a topic of discussion and interest, particularly to explain the mechanistic changes such as the presence or absence of turbulence. 
The transition from laminar to turbulent regime is a process that begins with the formation, amplification and development of small two-dimensional waves into finite three-dimensional waves. Following, these waves are amplified by nonlinear interactions and turbulent spots are formed. Finally, the propagation of turbulent spots fills the entire flow field [6].

Drag or resistance is strongly affected by fluid properties (i.e. viscosity) and geometrical features of the solid (i.e. size and shape) and is particularly related to a reference area. Drag coefficient has been studied by several researchers SalinasTapia and coworkers [7] elucidated the effects of interaction between the fluid and the solids after transport analysis of a mixture of quasi - uniform sediments in conditions of liquid and solid flow variation. The effects showed to have an impact on the flow properties, such as turbulence and speed of falling particles. Accordingly, they used Particle Image Velocimetry to determine fall velocities for particles of different size suspended, which was difficult to achieve with other conventional methods such as Acoustic Doppler Velocimetry or Laser Doppler Velocimetry. It was also found that the increment in flow turbulence decreased the Reynolds number of the particles and as a consequence, the drag coefficient increased in the smaller particles and decreased significantly the rate of fall as the Reynolds increased. Further research is still necessary to fully understand the relationship between Reynolds parameter and drag coefficient of the particles, in order to obtain a method that could estimate the velocity of a particle falling after increasing the turbulent regime.

Imron and Suryanto studied the mathematical model of drag coefficients on Reynolds parameter [8]. They analyzed a fluid flowing through a tandem configuration of a circular cylinder considering different values of distance and Re with the consideration of Navier-Stokes equations and applying the finite difference method. Navier-Stokes equations, are commonly used to express the motion of viscous fluids [9]. Research has been performed about fluids in motion by means of mathematical modeling using boundary element method, the study of pressure and temperature distribution and estimation of fluid film thickness as discussed in [10] [11] and [12]. Additionally, an algorithm was designed and validated to study nonisothermal two-phase flow with free surface [13]. Research on numerical simulation parameters, geometry and mesh on fluid flow around a large number of trash-racks combinations and comparison with experimental results from literature has been reported recently [14]. An experimental method that can be used for investigation of mixing phenomena in double tee-junctions placed at different distances was reported by Lucin and coworkers. The experimental methodology presented could be used to observe the influence of distances between two tee-junctions and different inflow rates on mixing. Additionally, evaluated experimental results can be suseful to provide more accurate mixing parameters and thus improve develped programs for simulation purposes [15].

In this paper, we study the laminar boundary layer on a solid and also discuss the case of turbulent flow. Furthermore, we determine the boundary layer thickness and discuss two methods to estimate drag coefficient at different distances from the leading edge.

\section{Transition point to turbulent boundary layer}

\subsection{Thickness of laminar boundary layer}

The thickness value of the laminar boundary layer on a flat surface can be calculated as $Z_{x}=5.5 \sqrt{\mu \delta / \rho \bar{v}}$. The Reynolds parameter based on thickness $(\delta)$ is given by $R e_{\delta}=(\bar{v} \delta \rho) / \mu$. Reynolds number based on $Z_{x}$ can be described as presented in (1), therefore, after substitution of proper relationships we obtain the following equations and simplifications:

$$
R e_{Z}=\left(\bar{v} Z_{x} \rho\right) / \mu=(5.5 \bar{v} \sqrt{\mu \delta / \rho \bar{v}} \rho) / \mu=5.5 \sqrt{\rho \bar{v} \delta / \mu}=5.5 \sqrt{\operatorname{Re}_{\delta}}
$$

Since the range of $R e_{\delta}$ is between $10^{5}$ and $3 \times 10^{6}$,

$$
R e_{Z}=5.5 \sqrt{\left(1 \times 10^{5}\right)} \text { to } 5.5 \sqrt{\left(3 \times 10^{6}\right)}=1.74 \times 10^{3} \text { to } 9.5 \times 10^{3}
$$

For laminar flow in a tube, Reynolds number is normally less than $3 \times 10^{3}$. Therefore at the transition to the turbulent flow, the Reynolds number based $\mathrm{Z}_{\mathrm{x}}$, instead of on $\delta$ is close to the transition Reynolds number for flow in a tube.

The determination of transition length value $\left(x_{t}\right)$ at the entrance to a tubes or pipes of different diameters can be estimated for particular substances. We present in Table 1 the case of glycerol and nominal pipe size in a range of 10 to $50 \mathrm{~mm}$ diameter tube and flow velocity of $0.5 \mathrm{~m} / \mathrm{s}$. The transition length can be evaluated after expression (3). Further, we present in Figure 1 the variation of transition length at different values of tube diameter and flow velocity with constant viscosity and density and the variation of Reynolds number at different values of tube diameter and flow velocity with constant viscosity and density in Figure 2.

$$
x_{t}=(0.05 \cdot R e \cdot D)=(0.05 \cdot(\bar{v} \delta \rho) / \mu)=(0.05 \cdot[(0.5 \cdot \delta \cdot 1240) / 0.098] \cdot D)
$$




\begin{tabular}{|c|c|c|c|c|c|c|}
\hline substance & $\operatorname{viscosity}(\mathbf{P a} \cdot \mathbf{s})$ & $\begin{array}{l}\text { density } \\
\left(\mathrm{kg} / \mathrm{m}^{3}\right)\end{array}$ & $\begin{array}{c}\text { flow velocity } \\
(\mathbf{m} / \mathbf{s})\end{array}$ & $\begin{array}{c}\text { Diameter of } \\
\text { tube (m) }\end{array}$ & $\operatorname{Re}$ & $\begin{array}{c}\text { transition length } \\
(\mathbf{m m})\end{array}$ \\
\hline \multirow{5}{*}{ glycerol } & \multirow{5}{*}{0.098} & \multirow{5}{*}{1240} & \multirow{5}{*}{0.5} & 0.01 & 63.26 & 31.63 \\
\hline & & & & 0.02 & 126.5 & 126.53 \\
\hline & & & & 0.03 & 189.7 & 284.69 \\
\hline & & & & 0.04 & 253.0 & 506.12 \\
\hline & & & & 0.05 & 316.3 & 790.81 \\
\hline
\end{tabular}

Table 1. Determination of transition length values $(\mathrm{mm})$ at different values of tube diameter $(\mathrm{m})$ and Reynolds number

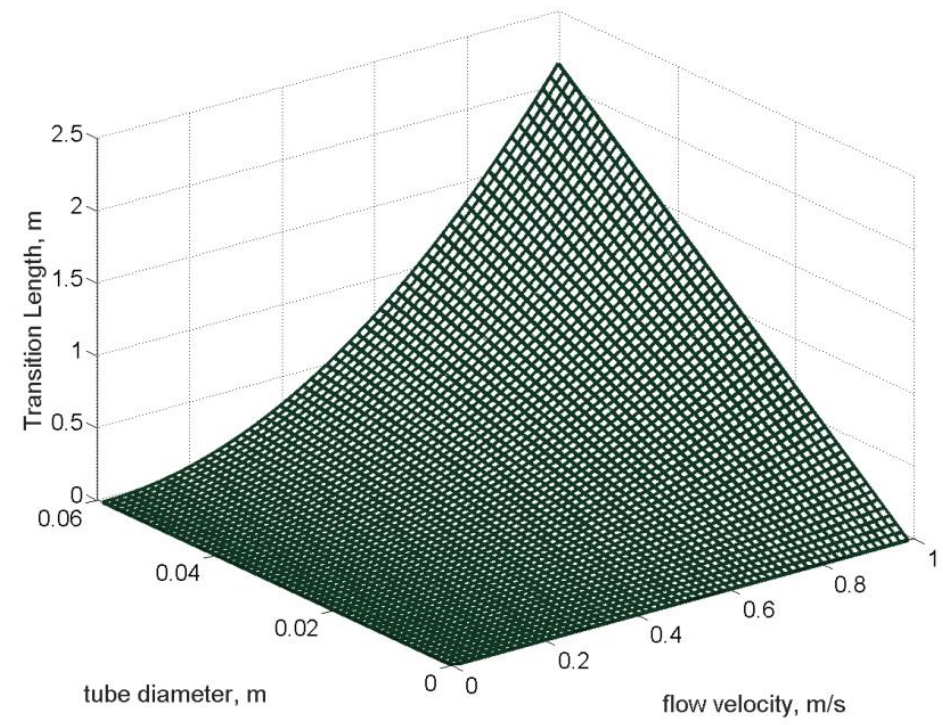

Fig. 1. Variation of Transition length $(\mathrm{m})$ at different values of tube diameter $(\mathrm{m})$ and flow velocity (m/s) with constant viscosity $(\mathrm{Pa} \cdot \mathrm{s})$ and density $\left(\mathrm{kg} / \mathrm{m}^{3}\right)$

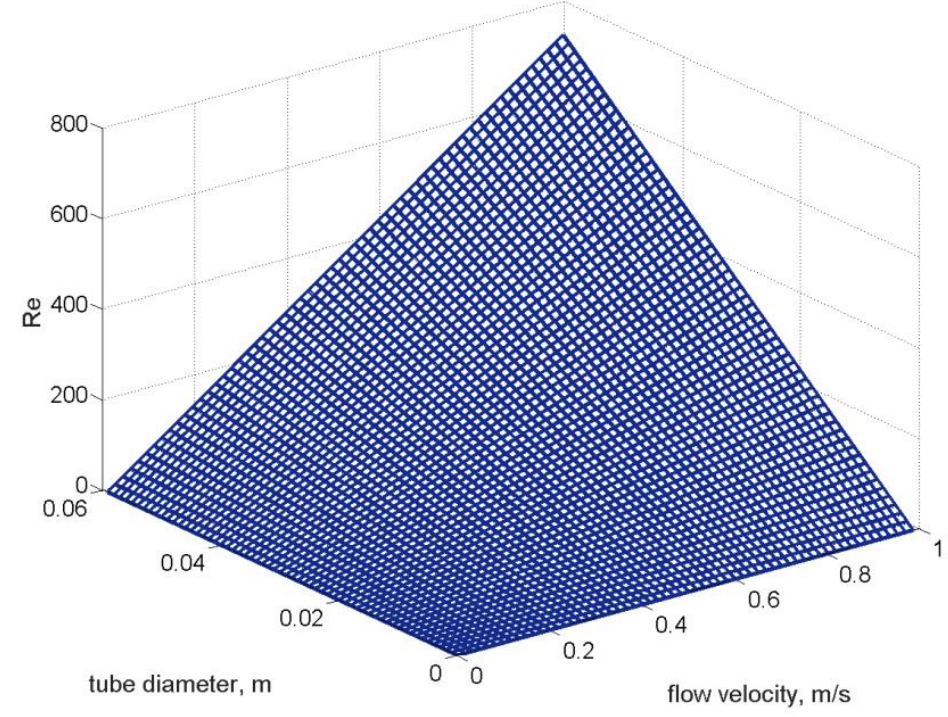

Fig. 2. a) Variation of Reynolds number at different values of tube diameter $(\mathrm{m})$ and flow velocity $(\mathrm{m} / \mathrm{s})$ with constant viscosity $(\mathrm{Pa} \cdot \mathrm{s})$ and density $\left(\mathrm{kg} / \mathrm{m}^{3}\right)$ 
We proceed now to discuss the determination of the distance from the leading edge at the point when transition occurs. For numerical purposes, we consider a flow of air of $15 \mathrm{~m} / \mathrm{s}$ through a smooth surface at $101.3 \mathrm{kPa}$ and $20{ }^{\circ} \mathrm{C}$, and the properties of air, namely viscosity of $1.983 \times 10^{-5} \mathrm{~N} \cdot \mathrm{s} / \mathrm{m}^{2}$ and density of $1.204 \mathrm{~kg} / \mathrm{m}^{3}$. Further, the transition from a laminar to a turbulent boundary layer happens at $R e_{x}=500000$. Thus we substitute the previous values in expression (4) as described next:

$$
x=\frac{R e_{x}(\mu)}{\bar{v} \rho}=\frac{500000\left(1.983 \times 10^{-5} \mathrm{~N} \cdot \mathrm{s} / \mathrm{m}^{2}\right)}{15 \mathrm{~m} / \mathrm{s} \cdot 1.204 \mathrm{~kg} / \mathrm{m}^{3}}=0.54 \mathrm{~m}
$$

We proceed to determine the thickness of the boundary layer at different leading edge distance values $(x)$, thus, for $\mathrm{x}=0.15 \mathrm{~m}$

$$
\begin{aligned}
& R e_{x}=\left[\left(0.15 \mathrm{~m} \cdot 15 \mathrm{~m} / \mathrm{s} \cdot 1.204 \mathrm{~kg} / \mathrm{m}^{3}\right) / 1.983 \times 10^{-5} \mathrm{~N} \cdot \mathrm{s} / \mathrm{m}^{2}\right]=1.36 \times 10^{5} \\
& \delta=\frac{5.0 \cdot x}{\sqrt{R e_{x}}}
\end{aligned}
$$

The previous value corresponds to the laminar region. Further, according to the works developed by Blasius and Howarth, the thickness of the boundary layer can be estimated as described in (6). Thus:

$$
\delta=\frac{5.0 \cdot 0.15}{\sqrt{1.36 \times 10^{5}}}=0.002 \mathrm{~m}
$$

We proceed to determine the value of $\delta$ at a higher leading edge distance $(\mathrm{x}=0.9 \mathrm{~m})$

$$
R e_{x}=\left[\left(0.9 \mathrm{~m} \cdot 15 \mathrm{~m} / \mathrm{s} \cdot 1.204 \mathrm{~kg} / \mathrm{m}^{3}\right) / 1.983 \times 10^{-5} \mathrm{~N} \cdot \mathrm{s} / \mathrm{m}^{2}\right]=8.2 \times 10^{5}
$$

The previous value corresponds to the turbulent region. Further,

$$
\delta=\frac{0.376 \cdot x}{R e_{x}^{1 / 5}}=\frac{0.376 \cdot 0.9}{\left(8.2 \times 10^{5}\right)^{1 / 5}}=0.022 \mathrm{~m}
$$

The previous value obtained is an approximate value since the turbulent boundary layer is assumed to extend to $\mathrm{x}=0$. Actually $\mathrm{x}=0.54 \mathrm{~m}$ of $0.9 \mathrm{~m}$. Hence, a considerable fraction is in laminar region.

An alternative and more accurate method to estimate $\delta$ at $0.09 \mathrm{~m}$ is to determine $\delta$ for laminar boundary layer for $R e_{x}=500000$ at $x=0.54 m$ as described next:

$$
\delta=\frac{5.0 \cdot 0.54}{\sqrt{5 \times 10^{5}}}=0.0038 \mathrm{~m}
$$

For turbulent boundary layer, $\delta=0.0038 m, R e_{x}=500000$

$$
0.0038=\frac{0.376 \cdot x}{\left(5 \times 10^{5}\right)^{1 / 5}}
$$

Thus, $x=0.14 \mathrm{~m}$ and the length $x$ for turbulent boundary layer is estimated as

$$
\begin{aligned}
& x=0.9 m-0.54 m+0.14 m=0.5 m \\
& \delta=\frac{0.376 \cdot 0.5}{\left(8.2 \times 10^{5}\right)^{1 / 5}}=0.0123 m
\end{aligned}
$$

Following, the drag coefficient is calculated at both distances $(L=0.15 \mathrm{~m}$, and $L=0.9 \mathrm{~m})$. In the case of laminar flow, $R e_{L}=1.36 \times 10^{5}$

$$
C_{D}=1.328 \sqrt{\frac{\mu}{L \bar{v} \rho}}=\frac{1.328}{\sqrt{R e_{L}}}=\frac{1.328}{\sqrt{1.36 \times 10^{5}}}=0.0036
$$


Low Reynolds numbers are associated to particular values of laminar drag as it also occurs at high Reynolds numbers. Between these numbers there is an extensive transition region. Numerical agreement between theoretical analysis and experimental determinations of laminar flow drag and heat transfer coefficients have been observed previously. Numerical analysis of turbulent flow is more complex but experimental data has also agreed with correlations of dimensionless parameters such as Reynolds and Prandtl numbers.

Accordingly, the estimation of drag coefficient $C_{D}$ and total drag $T_{D}$ for $0.9 \mathrm{~m}$ can be also performed. However, in this case it is not possible to use the expression (15)

$$
C_{D}=\frac{0.072}{\left(R e_{L}\right)^{1 / 5}}
$$

The turbulent boundary layer extends to $x=0$, since a substantial fraction of the total length of $L=0.9 \mathrm{~m}$ is laminar $(x=0.54 m)$, we proceed to use an approximation by calculating $C_{D}$ and $T_{D}$ for $L=0.9 \mathrm{~m}$ using the turbulent equation described in (16)

$$
C_{D \text { turb }}=\frac{0.072}{\left(8.2 \times 10^{5}\right)^{1 / 5}}=0.004727
$$

The result from previous equation would be accurate if the laminar length of plate is small. The drag depends directly on the physical dimensions of the solid. Drag $\left(T_{D}\right)$ is equal to the drag coefficient $\left(C_{D}\right)$ times the density times half of the velocity squared times the reference surface area $(S)$. Thus, using the equation to evaluate drag coefficient related to the total drag on one side of the plate we obtain:

$$
T_{D \text { turb }}=\left[C_{D \text { turb }} \frac{\bar{v}^{2} \cdot \rho \cdot S}{2}\right]=0.004727 \frac{(15)^{2} \cdot 1.204 \cdot(0.3 \times 0.9)}{2}=0.17 \mathrm{~N}
$$

Next, we determine $C_{D \text { crit }}$ and $T_{D \text { crit }}$ for turbulent length at $x=0.54 m$

$$
\begin{aligned}
C_{D \text { crit }} & =\frac{0.072}{\left(5 \times 10^{5}\right)^{1 / 5}}=0.0052 \\
T_{D \text { crit }} & =0.0052 \frac{(15)^{2} \cdot 1.204 \cdot(0.3 \times 0.54)}{2}=0.114 \mathrm{~N}
\end{aligned}
$$

Accordingly, we estimate $C_{D \text { lam }}$ and $T_{D \text { lam }}$ for laminar length at $x=0.54 m$

$$
\begin{aligned}
& C_{D}=\frac{1.328}{\sqrt{5 \times 10^{5}}}=0.0018 \\
& T_{D \text { lam }}=0.0018 \frac{(15)^{2} \cdot 1.204 \cdot(0.3 \times 0.54)}{2}=0.039 \mathrm{~N}
\end{aligned}
$$

Thus, the resultant value $C_{D}$ and $T_{D}$ for $\mathrm{L}=0.9 \mathrm{~m}$

$T_{D}=\left(T_{D \text { turb }}-T_{D \text { crit }}+T_{D \text { lam }}\right)=(0.17-0.114+0.039)=0.095$

Finally, this leads to:

$$
0.095=C_{D \text { turb }} \frac{(15)^{2} \cdot 1.204 \cdot(0.3 \times 0.9)}{2} ; C_{D \text { turb }}=0.0026
$$

There exists drag caused by friction between the fluid and the body. The frictional force is proportional to the square of the relative velocity of the object with respect to the fluid and the proportionality constant called drag coefficient $\left(C_{D}\right)$ which in turn depends on the Reynolds number. Drag is strongly influenced by a complex dependence of fluid's properties such as density, viscosity and compressibility, the square of the velocity, the size and shape of the body, and the solid's inclination to the flow. There are formulas that describe with greater or less approximation the measurements of the drag coefficient for an object of particular geometrical shapes in a wide range of Reynolds numbers, Re. For example, in the case of sphere it is possible to evaluate drag coefficient according to (25) and (26). As we can see in the comparison presented in Figure 3, both descriptions agree in a wide range of Reynolds number, except in the area where a rapid change in drag coefficient occurs $\left(\operatorname{Re}>2 \times 10^{5}\right)$. For Reynolds numbers of the order of $10^{4}$ to $2 \times 10^{5}$ the drag coefficient remains almost constant close to $C_{D}=0.4$ 


$$
\begin{aligned}
& C_{D}=\left[\frac{24}{R e}+\frac{2.6\left(\frac{R e}{5}\right)}{1+\left(\frac{R e}{5}\right)^{1.52}}+\frac{0.411\left(\frac{R e}{2.63 \times 10^{5}}\right)^{-7.94}}{1+\left(\frac{R e}{2.63 \times 10^{5}}\right)^{-8}}+\frac{R e^{0.8}}{4.61 \times 10^{5}}\right] \\
& C_{D}=\sqrt[0.52]{\left(\frac{24}{R e}\right)^{0.52}+0.32^{0.52}}
\end{aligned}
$$

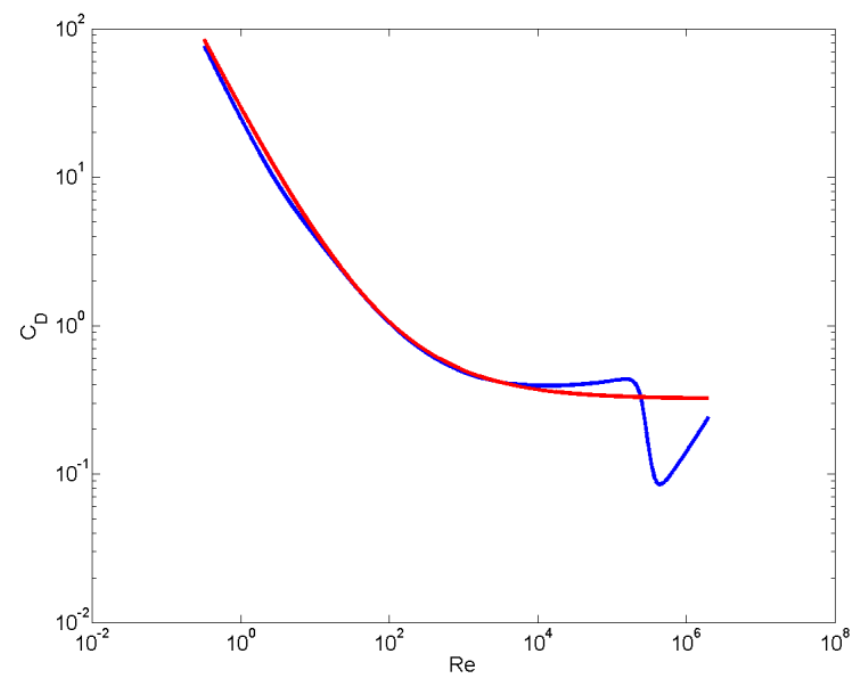

Fig. 3. Estimation of drag coefficient according to expressions (44) (blue line) and (45) (red line)

The study of boundary layer and fluid in motion is important in several fields of industry. Accordingly, with the interaction between fluids and objects occurs the generation of aerodynamic forces. Geometrical parameters of the object, rate of movement, psychochemical fluid properties (i.e. mass, viscosity and compressibility) influence the magnitude of such forces. Engineers take into account the values of these magnitudes as well as values of several dimensionless parameters to model the proper effects. When fluid molecules stick to the surface of a solid, a fluid layer near the surface is formed, determined as boundary layer. The flow of fluid reacts to the edge of the boundary layer as if it was the physical surface of the object. It is possible also that the boundary layer will form a different effective shape. Flow conditions in the boundary layer zone change constantly in time. From the engineering point of view, it is considerably important the understanding of the boundary layer, the use of numerical methods, predictive analytics, modeling, data analysis, software development and wind tunnel testing in determining the drag of a solid in order to determine and predict several conditions. Wind tunnels are often designed for full scale testing and are particularly important to test models of proposed aircrafts. It is extremely helpful as it allows the control of flow conditions which could affect forces on an aircraft and thus understand and improve the performance of the aircraft. Fluid molecules move around the solid as the object moves through the fluid. The speed at which the object moves affects the density and thus affects the amount of resulting force. Shock waves are produced as the object increases its speed near the speed of sound and affect the lift and drag the solid.

\section{Conclusions}

One of the most important factors that influence thermal transfer is the resistance to thermal flux through several "layers" that form the barrier between both fluids. The driving force for thermal transfer is the temperature differences between hot and cold fluids, the greater the difference, the higher the rate at which heat will flow between them. Thus, the designer task is to optimize the temperature levels at each stage to maximize the total heat transfer rate. The resistance to thermal transfer consists of several layers, such as the internal boundary layer formed by the fluid that moves in close contact with the inner surface of the tube, the layer formed by depositions of solids or semi-solids in the inner wall of the tube and also on the outer surface of the tube, the thickness of the tube wall and the material used will influence the resistance to heat flow through the tube itself, the external boundary layer formed by the flow that moves in contact with the outer surface of the tube.

It is common that some values are already specified as a result of the experience, while the specifications of diameter and length of the tube are additionally performed, as well as the thickness and the materials suitable for the application. The heat flux resistance resulting from the internal and external boundary layers, depends largely on the nature of the fluids and also on the geometry of the surfaces. It is important to note that the final values are strongly influenced by the boundary layers, as the fluid is in contact with the thermal transfer surface. 
Determination of drag is important in several engineering areas. Surface area considered for the analysis can be different. It is possible to consider the friction between the fluid and the solid; in this case the total surface area of the body is determined. In the case of analyzing the resistance to the flow, the frontal area of the body which is perpendicular to the direction of the fluid flow is taken into account, and in case of lift coefficient analysis, the same area used to derive the lift coefficient is measured. As experiments are often performed to measure drag and the area the selection depends strongly on which area is possible or easier to measure. Even if the estimated coefficients are different, the drag is the same. In practice, drag coefficients are registered according to different solids. In any case, it will be necessary to convert the drag coefficient using the ratio of the areas.

\section{Acknowledgments}

This work was supported by the Ministry of Education, Youth and Sports of the Czech Republic within the National Sustainability Programme project No. LO1303 (MSMT-7778/2014).

\section{References}

[1] Bird R.; Stewart E.; \& Lightfoot NE (2002). Transport Phenomena, John Wiley \& Sons, Inc, ISBN 9780470115398 New York.

[2] Coulson J.; Richardson J. \& Backhurst JR, (1999). Chemical engineering. Vol. 1, Fluid flow, heat transfer and mass transfer, Butterworth-Heinemann ISBN 9780750644440, Oxford.

[3] Emmons, H. W. (1951). The Laminar-Turbulent Transition in a Boundary Layer-Part I. Journal of the Aeronautical Sciences, Vol. 18, pp. 490-498., doi: 10.2514/8.2010

[4] Geankoplis, C. (1993). Transport processes and unit operations, Prentice Hall, ISBN 978-0131013674, New Jersey, USA.

[5] Cengel Y, \& Turner R (2001). Fundamentals of Thermal-Fluid Sciences, McGraw-Hill Higher Education, ISBN 978-0078027680, Singapore.

[6] Brodkey, R. S., \& Hershey, H. C. (2003). Transport phenomena: a unified approach. Brodkey Publishing. ISBN-13: 978- 0070079632 New York.

[7] Salinas-Tapia, H., García-Aragón, J., \& Díaz-Delgado, C. (2008). Experimental analysis of turbulence effect in settling velocity of suspended sediments. Ingeniería, Investigación y Tecnología, Vol. 9, pp. 49-58.

[8] Imron, C. (2016). Mathematical Model of Drag Coefficients on Reynolds Number. International Mathematical Forum, Vol. 11, pp. 817-822.

[9] Kuzmin, A; Popov V \&, Stazhkov S (2016). Rotation Transmission Device in High Ambient Hydrostatic Pressure Conditions. Chapter 22 DAAAM Int Sci B. doi: 10.2507/daaam.scibook.2016.22

[10] Kovacs, A \& Kovacs L (2011). Analyzing the fluid motion through network profiles using the boundary element method. Annals of DAAAM for 2011 \& Proceedings of the 22nd International DAAAM Symposium, Vol. 22, No.1, pp.1147-1148., ISSN 1726-9679

[11] Kovacs, A \& Kovacs L (2012). A hodographic approximation method for analyzing the fluid motion through network profiles. Annals of DAAAM for 2012 \& Proceedings of the 23rd International DAAAM Symposium, Volume 23, No.1,pp. 125-128., ISSN 2304-1382

[12] Muminovic A.; Repcic N, \& Colic M. (2014). Thermo Elasto Hydrodynamic Lubrication Model of Mixed Friction. Procedia Engineering in 24th DAAAM International Symposium of Intelligent Manufacturing and Automation, 2013, Katalinic B. (Ed.) Vol. 69, pp.49-56. doi: 10.1016/J.PROENG.2014.02.202

[13] Edin B. \& Šefko Š. (2015). Computational Modeling and Simulation of Nonisothermal Free-surface Flow of a Liquid Jet Impinging on a Heated Surface. Procedia Engineering in 25th DAAAM International Symposium of Intelligent Manufacturing and Automation 2014, Katalinic B. (Ed.), Vol. 100, pp.115-124. doi: 10.1016/J.PROENG.2015.01.349

[14] Carija, Z; Lucin, I; Lucin, B \& Grbcic, L (2018). Investigation of Numerical Simulation Parameters on Fluid Flow Around Trash-Racks. Proceedings of the 29th DAAAM International Symposium, B. Katalinic (Ed.), Vol. 29, No.1. pp.1046-1052. Published by DAAAM International. ISSN 1726-9679. DOI: 10.2507/29th.daaam.proceedings.149

[15] Lucin, I; Kranjcevic, L; Carija, Z \& Mogorovic, A (2018). Experimental Setup of Fluid Mixing in Double TeeJunctions. Proceedings of the 29th DAAAM International Symposium, B. Katalinic (Ed.), Vol. 29, No.1. pp.10591064. Published by DAAAM International. ISSN 1726-9679. DOI: 10.2507/29th.daaam.proceedings.151 